\title{
Predicting Optimum Dilution Factors for BOD Sampling and Desired Dissolved Oxygen for Controlling Organic Contamination in Various Wastewaters
}

\begin{abstract}
Hisham A. Maddah
Department of Chemical Engineering, Faculty of Engineering-Rabigh Branch, King Abdulaziz University, Jeddah 21589, Saudi Arabia

Correspondence should be addressed to Hisham A. Maddah; hmaddah@kau.edu.sa

Received 11 December 2021; Revised 10 January 2022; Accepted 29 January 2022; Published 21 February 2022

Academic Editor: Senthil Kumar Ponnusamy

Copyright $\odot 2022$ Hisham A. Maddah. This is an open access article distributed under the Creative Commons Attribution License, which permits unrestricted use, distribution, and reproduction in any medium, provided the original work is properly cited.

High biochemical oxygen demand (BOD) concentrations in water minimize oxygen availability, damage ecosystem biodiversity, impair water quality, and spoil freshwater. The increased level of BOD is an indication of severe organic pollution of freshwater. Thus, this study aims to establish empirical correlations between the 5-day biochemical oxygen demand $\left(\mathrm{BOD}_{5}\right)$ and organic decomposition time to control organic pollution in various wastewater effluents. Ultimate biochemical oxygen demand (UBOD) and minimum and average $\mathrm{BOD}_{t}$ data sets along with their reaction rates were collected from earlier sampling analyses in the plants used for industrial, domestic (sanitary), and storm (surface) wastewater treatment. Average $\mathrm{BOD}_{5} / \mathrm{COD}$ ratios were then utilized to calculate existing 5-day dissolved oxygen $\left(\mathrm{DO}_{5}\right)$ concentration for the estimation of experimental dilution factors (dfs) as a good start in sampling analysis to reach an optimum $\mathrm{DO}_{5}$ concentration. Moreover, the relationships between average $\mathrm{BOD}_{5}$ vs. $\mathrm{COD}$, and $\mathrm{BOD}_{5}$ vs. $\mathrm{DO}_{5}$, were obtained based on the literature with $60-70 \%$ oxygen consumption rates required for organic decomposition. Results showed that such $\mathrm{BOD}_{5}$ relationships with time (power equations) or with $\mathrm{COD}$ (linear correlations) are helpful for wastewater engineers to generate valuable and accurate results for quality control, without the need to conduct laboratory experiments. The proposed regression equations would facilitate effluent quality assessment, allowing selection of optimal processes to control microbiological contamination or organic constituents in wastewaters.
\end{abstract}

\section{Introduction}

Biochemical oxygen demand (BOD) is the oxygen demand of the organism to break down organic matter over a given period. Typically, organic pollution in freshwater bodies can be detected by the experimentally measured BOD levels from sampling analysis, which is directly correlated to microbiological contamination in sampled water [1].

The current projections of demographic growth and the increased demand for dairy products and consumption of meat prompted concerns regarding surface water quality due to the worsening of the global "sanitation crisis." Such climate change is expected because of the introduced sanitary issues in surface water bodies (especially rivers) that require reduction of discharge flows and/or dilution capability. BOD rates have been modeled on a global scale, which concluded that chemical wastes and organic discharges have a major impact on the world's economy if wastewater treatment progress is kept at current levels [2-4].

In Europe, a previous study projected an increase in organic pollution, especially in the southern countries, where most rivers have lost their dilution power as a result of the lack of dilution capacity of wastewater discharge in water-scarce areas. The study indicated that the eastern part of Europe and the Black Sea were to be more impacted by decreased river dilution capability and possible water quality deterioration [5]. The BOD parameter was chosen by the United Kingdom (UK) in 1908 as an indicator of the organic pollution of rivers enforced by the UK "Royal Commission on River Pollution." The traditional five-day period to estimate the $\mathrm{BOD}_{5}$ parameter was selected for this test because this is supposedly the longest time that river water takes to 
travel from its source to its delta (outlet end meeting a bay or an ocean) in the UK. Following that, the methods introduced in 1936 by the committee "American Public Health Association Standard" suggested using the BOD parameter as a reference indicator to evaluate the biodegradation of chemicals and hazardous substances. The use of the $\mathrm{BOD}_{5}$ parameter arises due to three major applications: (1) it is an indicator for the conformity of the wastewater discharge and the waste treatment procedures with the current up-to-date regulations, (2) it is required to obtain the ratio of $\mathrm{BOD}_{5}$ to chemical oxygen demand (COD) that would indicate the biodegradable fraction of effluent (discharge) from wastewater treatment plants, and (3) the ratio $\mathrm{COD} / \mathrm{BOD}_{5}$ is an indicator of the size of a wastewater treatment plant required for a specific location [6-9].

$\mathrm{BOD}_{5}$ is the amount of oxygen that is consumed by bacteria and other microorganisms to be aerobically degraded in a water medium over a 5-day span at a standard temperature of $20^{\circ} \mathrm{C}$. Therefore, the $\mathrm{BOD}_{5}$ is an indirect metric method for quantifying existing organic or chemical wastes that are biodegradable in presence of oxygen in water, expressed in $\mathrm{mg} \mathrm{O}_{2} / \mathrm{L}[10-13]$. $\mathrm{BOD}_{5}$ indicates the amount of $\mathrm{O}_{2}$ dissolved in $\mathrm{mg} / \mathrm{L}$ that is required in a particular time for biodegradation of the components of organic water waste. This value is an important parameter for the assessment of the degree of organic contamination that wastewater poses to the environment. The superficial flow of rainwater causes water to become contaminated, and this rainwater organic contamination can be analyzed by several parameters including $\mathrm{BOD}_{5}$. The importance of this parameter value lies in the evolution of the degree of the contamination of environmental wastewater. Since the wastewater contents or constituents in the receiving water are decomposed by the bacteria present in it, the oxygen is either completely or partially withdrawn from the water to carry such organic pollutants degradation [6-8].

Two well-known methods are widely used for BOD measurement: (1) the dilution method, which is the most common and recent BOD measurement method based on the American Public Health Association (APHA) standards that have been certified by the US Environmental Protection Agency (USEPA), and (2) the manometric system, which has been commonly used in many sewage plants and other facilities around the world for over 75 years [14]. However, the USEPA denied the approval of the latter method for wastewater analysis, although in certain cases the USEPA has approved the manometric method due to lack of data consistency and progress in associated laboratory techniques [15]. In short, measuring BOD requires taking a minimum of two measurements, one measurement for the current (immediate) or initial dissolved oxygen $\left(\mathrm{DO}_{0}\right)$, and the second measurement is after incubation of water samples in the lab for 5 days to be then tested for the remaining amount of final 5 -day dissolved oxygen $\left(\mathrm{DO}_{5}\right)$. Such experiments would allow us to quantify the amount of oxygen consumed by microorganisms to break down the organic matter present in the sample during the incubation period [10-13].

BOD is affected by the same factors that affect DO. High BOD-containing wastewaters will impact a minimum of 2.5 billion people by the year 2050. High BOD concentrations (e.g., $5 \mathrm{mg} \mathrm{O}_{2} / \mathrm{L}$ ) in water minimize oxygen availability, degrade aquatic habitats as well as ecosystem biodiversity, impair water quality, and spoil freshwater [5]. Sources of BOD include topsoil, leaves and woody debris, animal manure, and effluents from pulp and paper mills [10-13]. The high BOD loadings to freshwater and/or watershed systems are mainly coming from anthropogenic sources, as mentioned, comprising domestic and livestock (animal) waste, industrial emissions, agricultural pollutants, and combined or mixed sewer overflows. During their path in the stream network, BOD concentrations become lower with continuous microbial degradation, leading to river selfpurification, and self-revitalization, and dilution of BODcontaining wastewater before reaching the seas [5]. The higher the BOD value, the faster the oxygen in the stream is depleted. This suggests that higher levels of marine life have less oxygen available to them to be consumed aerobically. High BOD has the same effects as low dissolved oxygen where marine lives become suffocated and eventually die. Wastewater treatment plants, feedlots, food-processing plants, failing septic systems, and urban stormwater runoff can cause a spike in recorded BOD due to organic wastes in water [10-13].

In the present study, we aim to establish empirical correlations between $\mathrm{BOD}_{5}$ and organic decomposition time to control organic pollution. Ultimate biochemical oxygen demand (UBOD) and minimum and average $\mathrm{BOD}_{t}$ data sets along with their reaction rates were collected from the plants used for industrial, domestic (sanitary), and storm (surface) wastewater treatment. The characteristics of various wastewater effluents (which are actually influents to the different wastewater treatment plants) have been thoroughly studied. The ultimate BOD and reaction rates were collected to be used as input to calculate average $\mathrm{BOD}_{5} / \mathrm{COD}$ ratios and $\mathrm{DO}_{5}$ concentration for the estimation of experimental dilution factors (dfs) at various temperatures and times, that is a very important factor to know how much oxygen should be introduced, based on existing BOD, for successful and complete organic decomposition, allowing us to find the relationships between average $\mathrm{BOD}_{5}$ vs. $\mathrm{COD}$, and $\mathrm{BOD}_{5}$ vs. $\mathrm{DO}_{5}$. The proposed regression equations are believed to allow wastewater engineers to facilitate effluent quality assessment via selecting optimal processes that would control microbiological contamination, without the need for laboratory analysis.

\section{Methodology and Study Framework}

As discussed, the literature data were collected based on earlier BOD sampling analyses of various wastewater types including industrial, domestic (sanitary), and storm (surface) wastewater in different wastewater treatment plants. The previously collected laboratory data regarding $\mathrm{BOD}_{t}$ at their UBOD and minimum and average determined $\mathrm{BOD}_{t}$ values were then utilized to calculate the corresponding minimum and average constant reaction rates $\left(k_{1}\right)$ that would quantify organic decomposition rates in the studied BOD-containing sampled water. Then, the same identified $k_{1}$ 
was applied in the $\mathrm{BOD}_{t}$ fundamental formula in equation (1), knowing UBOD, to obtain $\mathrm{BOD}_{t}$ at various times for $t=0-60$ days with an increment rate of 5 days. The ultimate goal was to establish relationships between the $\mathrm{BOD}_{t}$ and organic decomposition time $(t)$ to control organic pollution in various wastewater effluents. Reaction rates were assumed to be constant numbers since we are treating the same wastewater type at the same plant (i.e., similar wastewater characteristics).

$$
\mathrm{BOD}_{t}=\operatorname{UBOD}\left(1-e^{-k_{1} t}\right) .
$$

We have also considered the impact of treating wastewater at lower temperatures than that already observed water temperatures in the various studied wastewater samples from selected wastewater plants. The same steps and/or train of calculations were followed to obtain $\left[\mathrm{BOD}_{t}\right.$ vs. time] correlations when wastewater is treated at lower feed temperature, from using the common $k_{1_{T}}$ temperaturedependent equation shown in equation (2) along with the predetermined $\theta$ constants and their temperature limits as reported in the literature $\left(\theta=1.056\right.$ for $T=20-30^{\circ} \mathrm{C}$ and $\theta=1.135$ for $T=4-20^{\circ} \mathrm{C}$ ) [16].

$$
k_{1_{T}}=k_{1_{20}} \theta^{T-20} .
$$

The second established and adopted train of calculations starts with obtaining the average $\mathrm{BOD}_{5} / \mathrm{COD}$ ratios that were later used in estimating the average laboratory dilution factors (dfs). It is worth mentioning that we carried out our analysis with a selected $\triangle \mathrm{DO}$ from $x=60-70 \%$ in equation (3), determined from $\mathrm{DO}_{0}$, where $\triangle \mathrm{DO}$ corresponds to organic decomposition associated with the oxygen consumption in water (final dissolved oxygen minus initial dissolved oxygen), knowing that $\mathrm{DO}_{0}$ at $20^{\circ} \mathrm{C}=9.1 \mathrm{mg} / \mathrm{L}$ for $\mathrm{BOD}_{5}$ (for domestic and industrial wastewaters) and that $\mathrm{DO}_{0}$ at $26.3^{\circ} \mathrm{C}=8.1 \mathrm{mg} / \mathrm{L}$ for $\mathrm{BOD}_{5}$ (for storm wastewaters). The chosen organic decomposition rate of $x=60-70 \%$ is considered a reliable range that has been previously applied in the simulation of oxygen saturation concentrations in wastewater in a sludge treatment plant in Jakarta at various temperatures. Also, from the list of oxygen concentrations at a certain temperature, it was found there is a standard $\mathrm{DO}_{0}$ at a maximum of $9.1 \mathrm{mg} / \mathrm{L}$ and a minimum of $7.5 \mathrm{mg} / \mathrm{L}$ at $20^{\circ} \mathrm{C}$ and $30^{\circ} \mathrm{C}$, respectively $[13,16,17]$.

$$
\Delta \mathrm{DO}=\mathrm{DO}_{5}-\mathrm{DO}_{0} \Rightarrow \mathrm{DO}_{5}=x \mathrm{DO}_{0} \text {. }
$$

We have calculated the estimated $\mathrm{df}$ from the known $\mathrm{BOD}_{5}, \mathrm{COD}$, and $\mathrm{DO}_{0}$ and the determined $\mathrm{DO}_{5}$ at $x=65 \%$ (average) based on equation (3), which would be input in equation (4) for $\mathrm{df}$.

$$
\mathrm{df}=\frac{\mathrm{BOD}_{5} /\left.\mathrm{COD}\right|_{\text {avg }} \times \mathrm{COD}_{\mathrm{avg}}}{\mathrm{DO}_{0}-\mathrm{DO}_{5}(\mathrm{mg} / \mathrm{L})} .
$$

For each of the studied wastewater types from the various wastewater treatment plants, we have plotted the relationship between $\mathrm{BOD}_{5}$ and $\mathrm{COD}, \mathrm{BOD}_{5}$ and df, as well as $\mathrm{BOD}_{5}$ against $\mathrm{DO}_{5}$ at $x=65 \%$. Such identified trendlines are believed to allow wastewater engineers and plant technicians or operators to adjust operating conditions accordingly for desired $\mathrm{DO}$ corresponding to feed $\mathrm{BOD}_{5} /$ COD ratios, which would ensure organic decomposition and smooth treatment operation. Figure 1 shows the study framework and the utilized step-by-step methods.

2.1. Data Collection and Data Set Curation. Data sets of industrial wastewater were curated based on 3 factories located in Ghana (Kumasi Metropolis, the capital city of Ashanti) namely Kumasi Abattoir, Coca-Cola, and GGL factories. From sampling methods and adopted data collection for industrial wastewater type, the $\mathrm{DO}_{5}$ content of liquid was determined by the Azide modification of Winkler's method before and after incubation for 5 days at $20^{\circ} \mathrm{C}$. Such calculated differences would give the $\mathrm{BOD}_{5}$ values of the sample after allowance had been made for the dilution. For optimum biochemical oxidation, the $\mathrm{pH}$ values of the samples were kept in the range of 6.5-8 to have consistent analysis [18]. Three various industrial plants were selected to gather their industrial wastewater $\mathrm{BOD}_{5}$ and $\mathrm{COD}$ so that $\mathrm{BOD}_{5}$ can be recalculated at different $k_{1}$ and different temperatures using the common $k_{1_{T}}$ temperature-dependent equation shown in equation (2) along with the predetermined $\theta$ constants and their temperature limits as reported in the literature $\left(\theta=1.056\right.$ for $T=20-30^{\circ} \mathrm{C}$ and $\theta=1.135$ for $T=4-20^{\circ} \mathrm{C}$ ) [16]. Again, we calculated $\mathrm{BOD}_{5}$ for 60 days, and in the last, we have taken the average $\mathrm{BOD}_{5} /$ COD for each plant to get dilution factors.

Regarding stormwater data collection, data sets have been collected from stormwater sources found in different countries. We collected the stormwater quality from the previously carried out sampling of stormwater runoff in the street, highway, surfaces, and parking, collected from different catchments in the selected three different countries (Bialystok-Poland, Abeokuta-Nigeria, Luxembourg), and previously taken for the analysis of pollutants including the parameter of interest here, $\mathrm{BOD}_{5}$. Similar calculation steps were followed here to recalculate the $\mathrm{BOD}_{5}$ in several storm wastewater plants to identify the relationship between $\mathrm{BOD}_{5}$ vs. COD in ordinary wastewater runoff or rainwater while correlating $\mathrm{BOD}_{5}$ to the initial dissolved oxygen and required dilution factors [6-8].

However, the collection of data and data set curation from various domestic wastewater treatment plants (three plants) was carried out based on data collected from AlDiwaniyah Wastewater Treatment Plant, the wastewater treatment plants of Jordan, and the North Sewage Treatment Plant in Dhahran, Eastern Province, Saudi Arabia. Typically, domestic wastewater treatment plants collect their samples to be analyzed and find the level of water contamination, and then water quality is compared with other plants' influents/ effluents in the industry for the achievement of less polluted wastewater via various treatment methods. For instance, wastewater stabilization ponds, activated sludge units, and trickling filters are some of the common strategies used for municipal wastewater treatment. Locally, 27 wastewater treatment plants distributed in the populated centers of Jordan are using the above-mentioned techniques for 


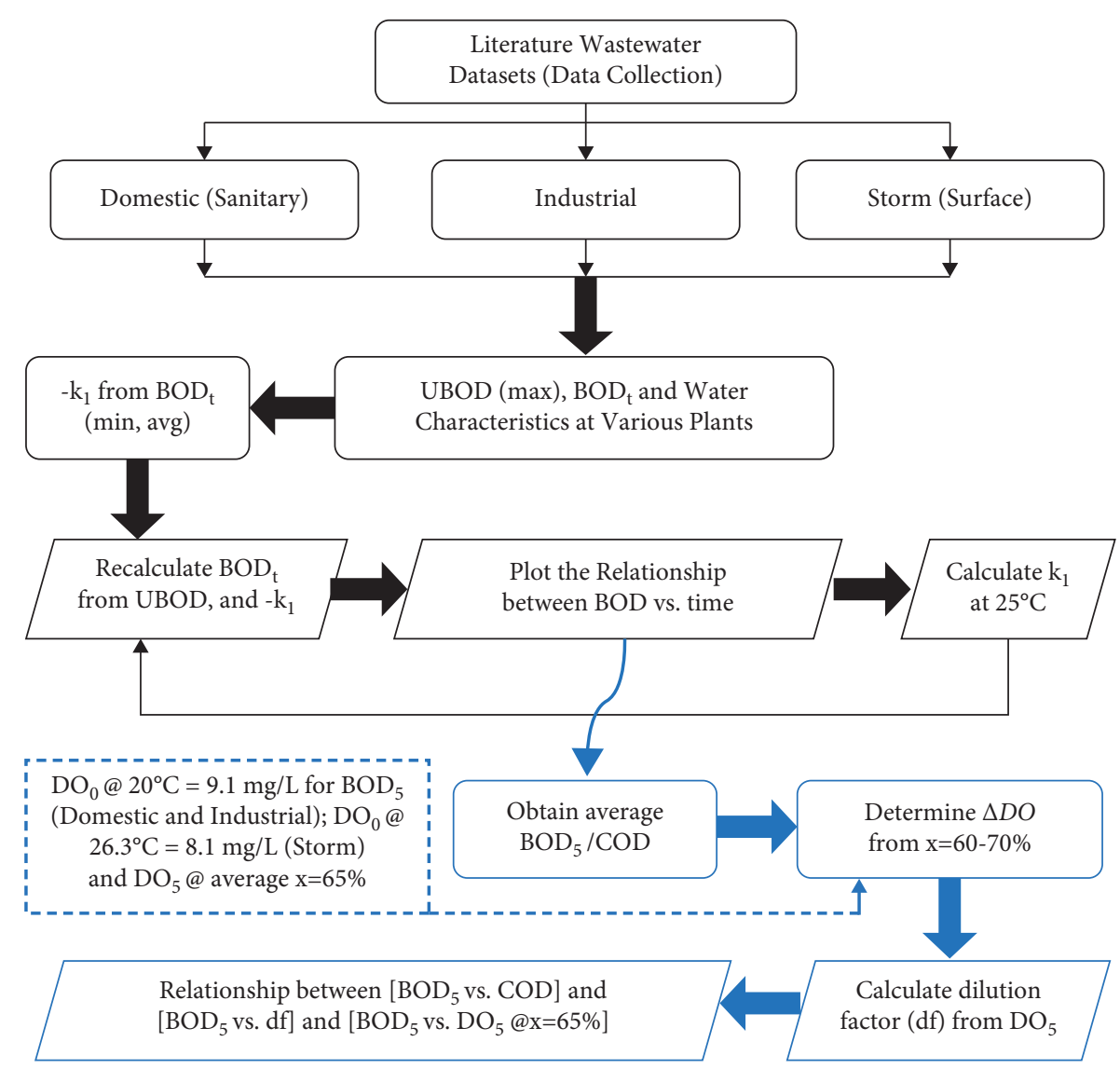

FIgURE 1: Study framework starting with data sets collection for determining $\mathrm{BOD}_{5}$-related relationships in the studied wastewater types from various wastewater treatment plants.

wastewater treatment. Such contamination can be investigated or attributed to the $\mathrm{BOD}_{5}$ level in collected samples for pilot-scaling to improve the treatment performance from changing organic loading rates or modifying designed hydraulic, or operating conditions, considering $\mathrm{pH}$, turbidity, TSS, COD, and BOD, for better effluent quality that would potentially reduce contamination to the environment and risk of ecosystem pollution $[10-13,19,20]$.

\section{Results and Discussion}

Herein, the study of how $\mathrm{BOD}_{t}$ changes over time concerning the three different wastewater types has been thoroughly discussed. Regarding the $\mathrm{BOD}_{t}$ for stormwater influents (from three different plants), the increasing $\mathrm{BOD}_{t}$ trendline with time was justified from raw data in the three selected plants, indicating the strong reliability of the existence of power relationships between $\mathrm{BOD}_{t}$ and time as illustrated in Figure 2. Both average and minimum $\mathrm{BOD}_{t}$ values $\left(k_{1} @ T=20^{\circ} \mathrm{C}\right)$ were plotted from the various storm wastewater plants, showing a mean range of an average $\mathrm{BOD}_{t} \approx 40-78 \mathrm{mg} / \mathrm{L}$ and a mean range of a minimum $\mathrm{BOD}_{t}$ $\approx 16-55 \mathrm{mg} / \mathrm{L}$, as plotted in Figures 2(a), 2(c), and 2(e). Similarly, the same analysis was carried out with $k_{1}$ @ $T=25^{\circ} \mathrm{C}$ to find the impact of temperature on the $\mathrm{BOD}_{t}$ mean ranges, which were found to increase the initial value (at $t=0$ ) by +6 (with a mean range of an average $\mathrm{BOD}_{t} \approx$
$46-78 \mathrm{mg} / \mathrm{L}$ and a minimum $\mathrm{BOD}_{t} \approx 22-60 \mathrm{mg} / \mathrm{L}$ from $k_{1} @$ $T=25^{\circ} \mathrm{C}$ ), as plotted in Figures 2(b), 2(d), and 2(f). This analysis justified the strong correlation and dependence of $\mathrm{BOD}_{t}$ on the water temperature, with an average of $+1.2 \mathrm{mg} / \mathrm{L}$ per every $1^{\circ} \mathrm{C}$ as a heat added to the water for the initial $\mathrm{BOD}_{t}$ values. It is worth mentioning that the power relationships were expected in all plants since they refer to the organic decomposition rates occurring in storm wastewater that would follow an exponential or a power pattern according to the previously discussed or derived equation (1) for $\mathrm{BOD}_{t}$.

Moreover, the $\mathrm{BOD}_{t}$ for industrial wastewater influents were observed with an obvious increase of $\mathrm{BOD}_{t}$ trendline with time. However, much higher $\mathrm{BOD}_{t}$ concentrations were there because industrial wastes contain very high amounts of organic compounds generated from various chemical and industrial processes. The power relationships between $\mathrm{BOD}_{t}$ and time were only accurate at low or minimum $\mathrm{BOD}_{t}$ of previously analyzed industrial wastewaters as illustrated in Figure 3. Such inaccuracies have been attributed to the rich organic constituents found with average $\mathrm{BOD}_{t}$ samples, making it very difficult for the oxygen-containing wastewater to degrade organics over a short period of 60 days (i.e., it requires either much longer time or very high added oxygen concentrations to see the power relationship between maximum $\mathrm{BOD}_{t}$ and time, instead of the linear trends). Plotted data sets showed a mean average $\mathrm{BOD}_{t}>90,000 \mathrm{mg} / \mathrm{L}$ (with 

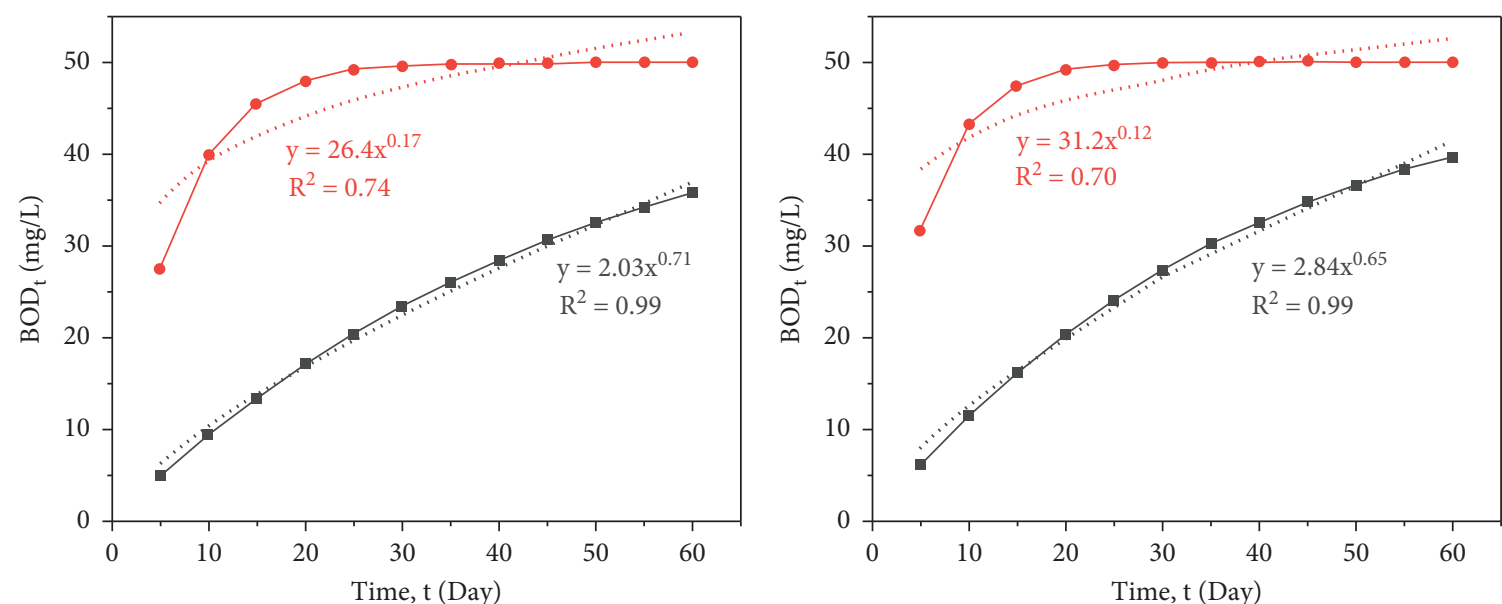

$\rightarrow \mathrm{BOD}_{\mathrm{t}}$ (avg)-Raw

...... $\mathrm{BOD}_{\mathrm{t}}$ (avg)-Fitted

$\rightarrow \mathrm{BOD}_{\mathrm{t}}(\mathrm{min})$-Raw

..... $\mathrm{BOD}_{\mathrm{t}}(\mathrm{min})$-Fitted

(a)

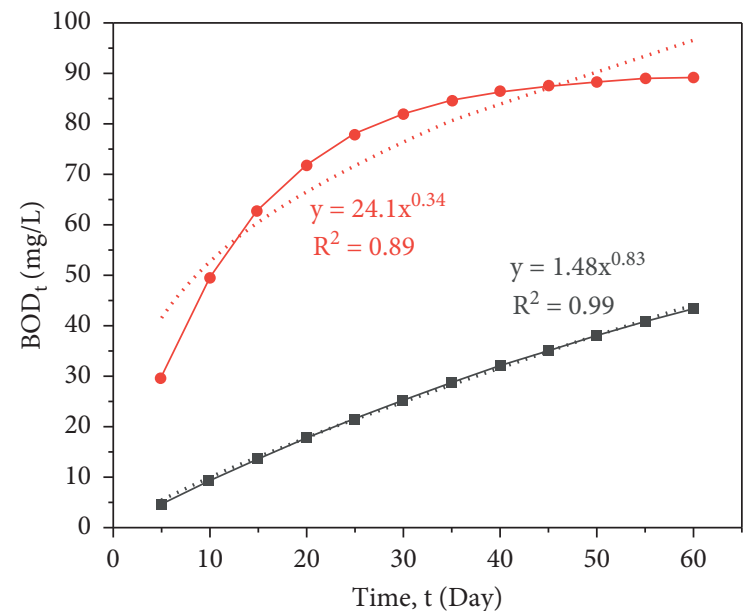

$\longrightarrow \mathrm{BOD}_{\mathrm{t}}$ (avg)-Raw

….. $\mathrm{BOD}_{\mathrm{t}}$ (avg)-Fitted

$\rightarrow \mathrm{BOD}_{\mathrm{t}}(\mathrm{min})-\mathrm{Raw}$

...... $\mathrm{BOD}_{\mathrm{t}}(\mathrm{min})$-Fitted

(b)

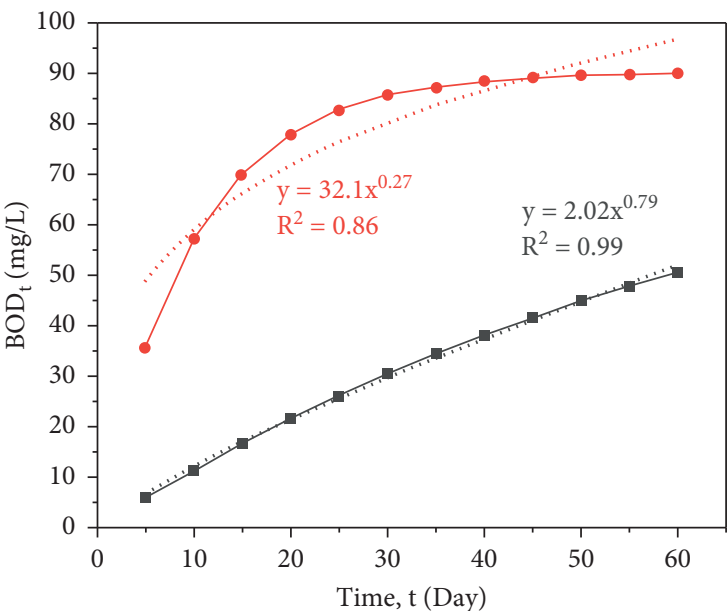

- $\mathrm{BOD}_{\mathrm{t}}$ (avg)-Raw

...... $\mathrm{BOD}_{\mathrm{t}}$ (avg)-Fitted

- $\mathrm{BOD}_{\mathrm{t}}$ (avg)-Raw

- BOD $_{\mathrm{t}}(\mathrm{min})$-Raw

,..... BOD $_{\text {t }}$ (avg)-Fitted

$-\mathrm{BOD}_{\mathrm{t}}(\mathrm{min})$-Raw

...... $\mathrm{BOD}_{\mathrm{t}}(\mathrm{min})$-Fitted

...... BOD $_{\mathrm{t}}(\mathrm{min})$-Fitted

(c)

(d)

Figure 2: Continued. 


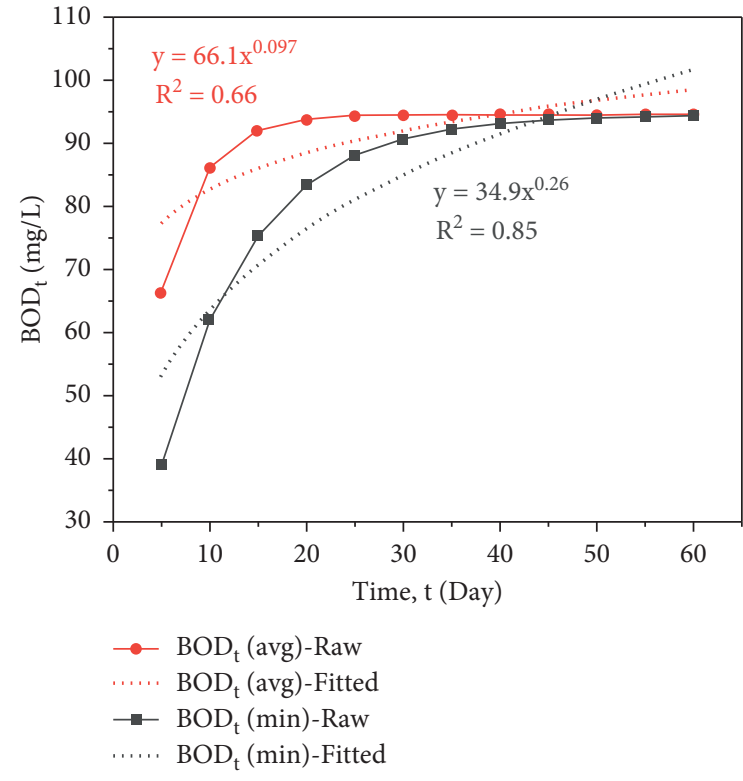

(e)

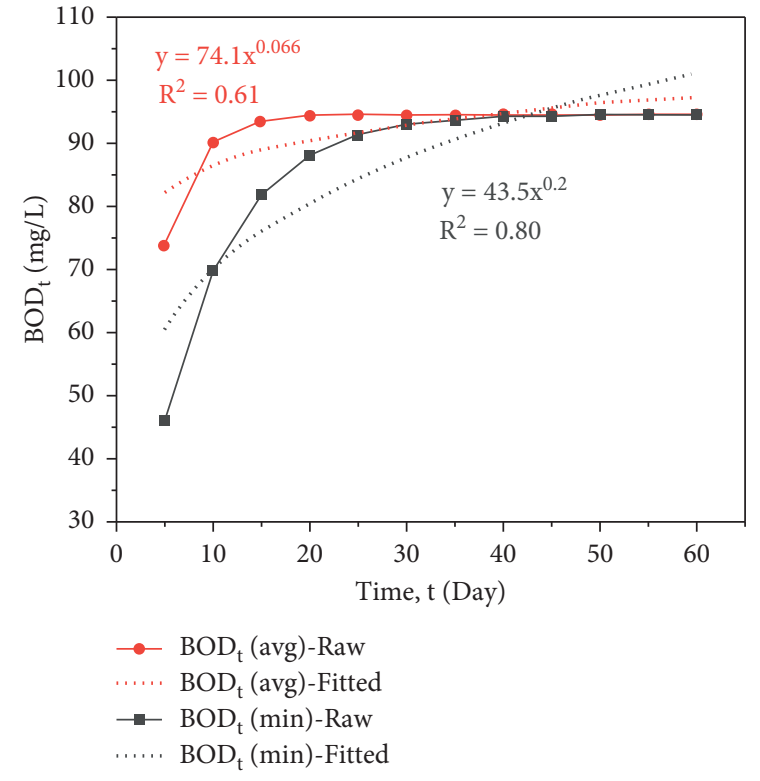

(f)

FIGURE 2: The determined fitted power relationships between $\mathrm{BOD}_{t}$ and time for 60 days of minimum and average $\mathrm{BOD}_{t}$ values collected from analysis of influents in various selected storm wastewater treatment plants: (a, b) Poland storm wastewater treatment plant with $k_{1} @$ $T=20^{\circ} \mathrm{C}$ and $k_{1} @ T=25^{\circ} \mathrm{C}$, respectively; (c, d) Luxembourg storm wastewater treatment plant with $k_{1} @ T=20^{\circ} \mathrm{C}$ and $k_{1} @ T=25^{\circ} \mathrm{C}$, respectively; and (e,f) Abeokuta-Nigeria storm wastewater treatment plant with $k_{1} @ T=20^{\circ} \mathrm{C}$ and $k_{1} @ T=25^{\circ} \mathrm{C}$, respectively.

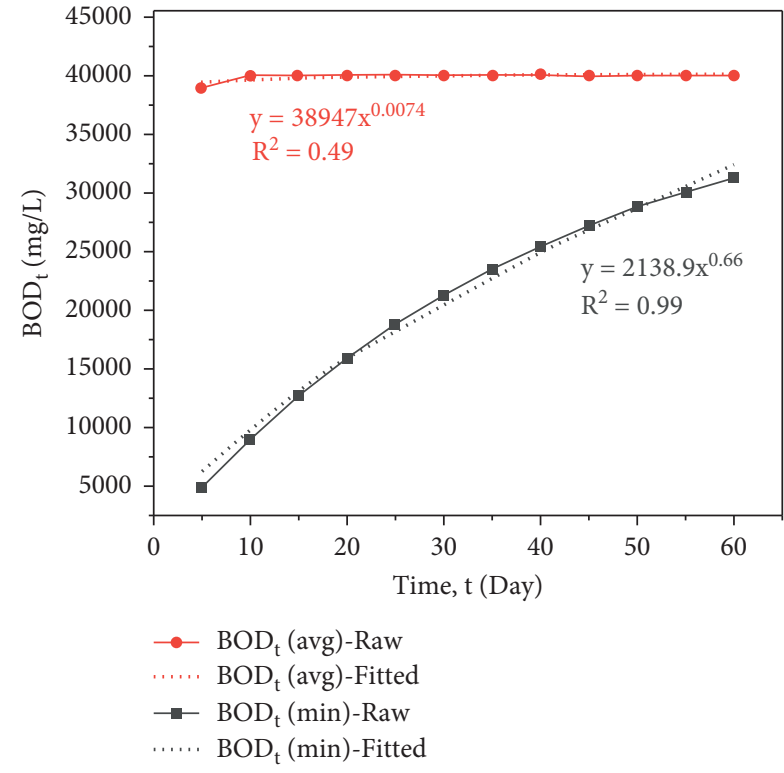

(a)

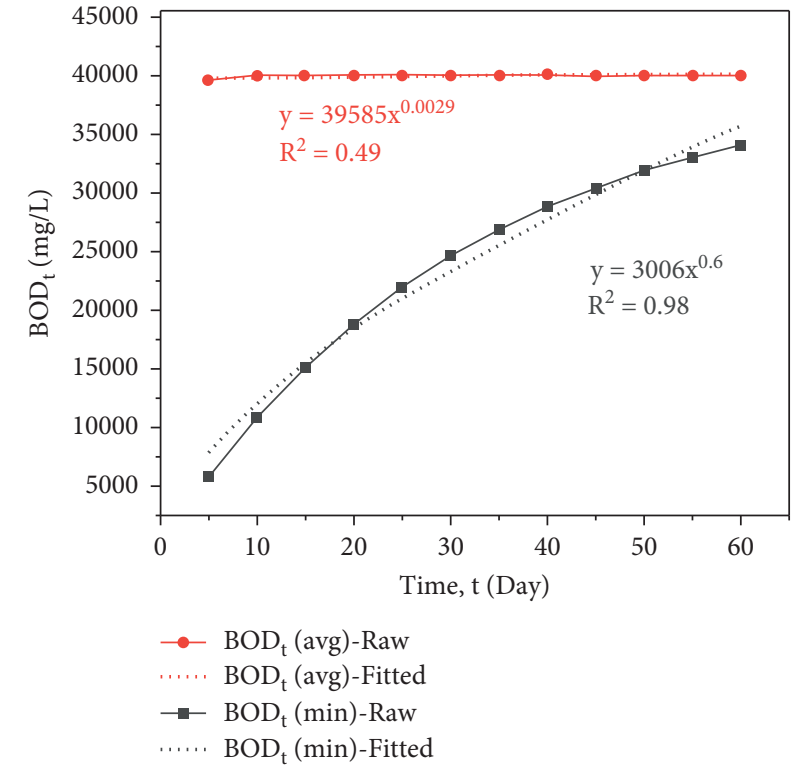

(b)

FIGURE 3: Continued. 


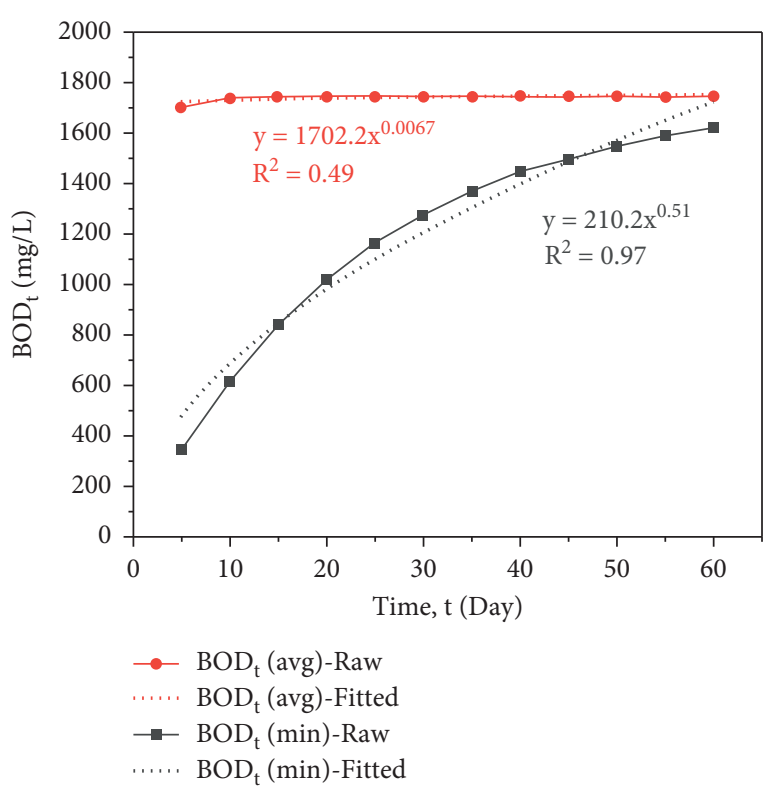

(c)

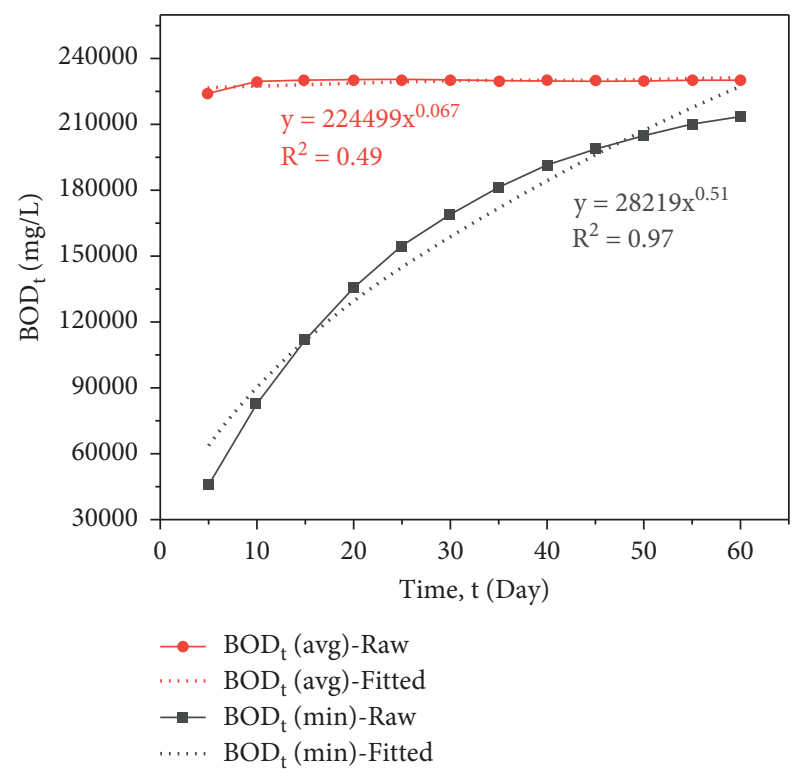

(e)

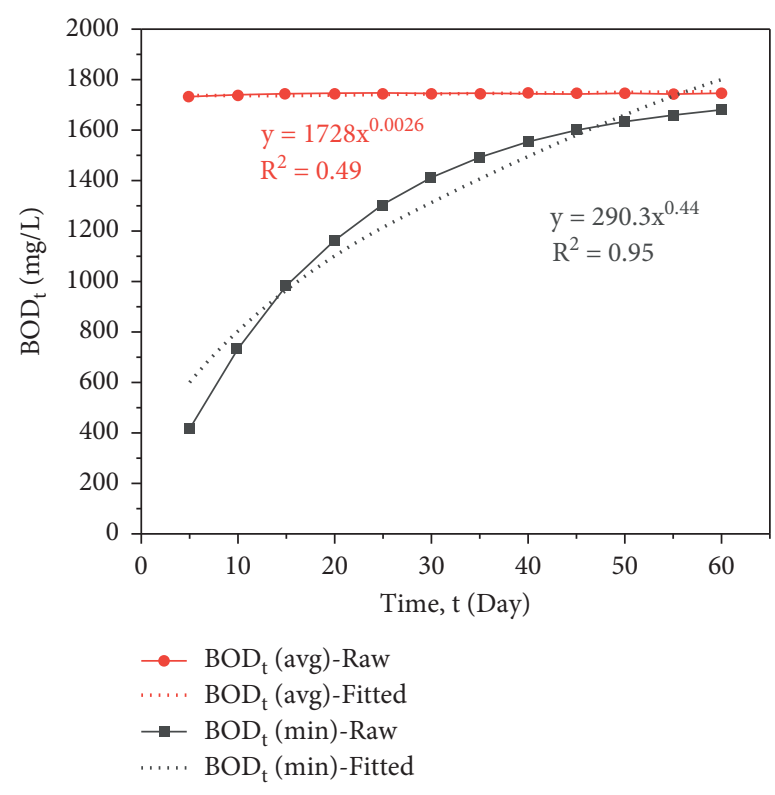

(d)

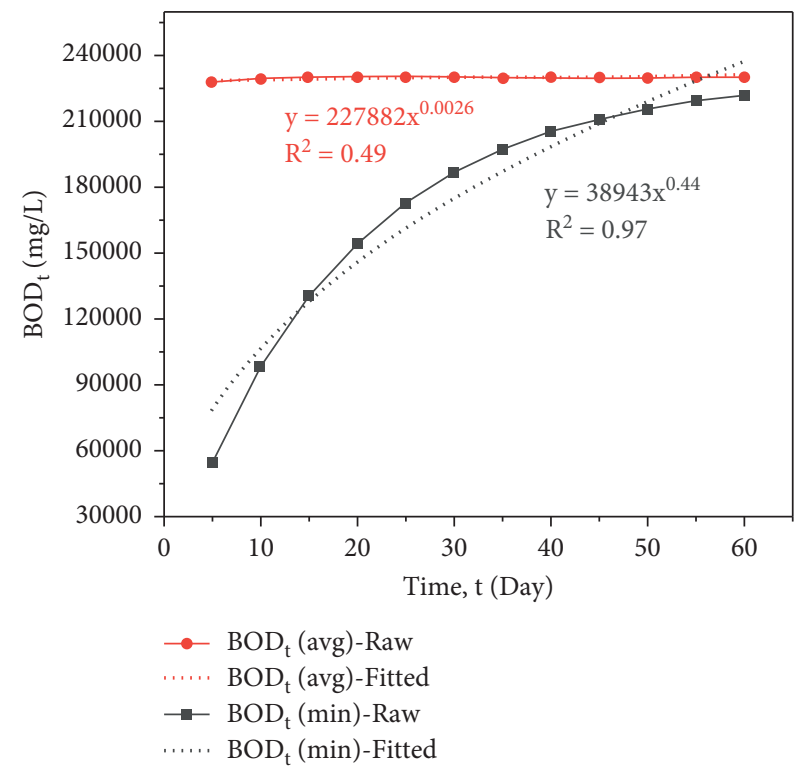

(f)

Figure 3: The determined fitted power relationships between $\mathrm{BOD}_{t}$ and time for 60 days of minimum and average $\mathrm{BOD}_{t}$ values collected from analysis of influents in various selected industrial wastewater treatment plants: (a, b) GGL industrial wastewater treatment plant with $k_{1} @ T=20^{\circ} \mathrm{C}$ and $k_{1} @ T=25^{\circ} \mathrm{C}$, respectively; (c, d) Coca-Cola industrial wastewater treatment plant with $k_{1} @ T=20^{\circ} \mathrm{C}$ and $k_{1} @ T=25^{\circ} \mathrm{C}$, respectively; and (e,f) Kumasi Abattoir industrial wastewater treatment plant with $k_{1} @ T=20^{\circ} \mathrm{C}$ and $k_{1} @ T=25^{\circ} \mathrm{C}$, respectively.

an average of $84,000 \mathrm{mg} / \mathrm{L}$ ) and a mean minimum $\mathrm{BOD}_{t}$ $<80,000 \mathrm{mg} / \mathrm{L}$, both from $k_{1} @ T=20^{\circ} \mathrm{C}$, as plotted in Figures 3(a), 3(c), and 3(e). Similarly, the same analysis was carried out with $k_{1} @ T=25^{\circ} \mathrm{C}$ to find the impact of temperature on the mean $\mathrm{BOD}_{t}$, which was found to increase the initial $\mathrm{BOD}_{t}($ at $t=0)$ by $+400 \mathrm{mg} / \mathrm{L}$ or $10 \%$ more than that of $k_{1} @ T=20^{\circ} \mathrm{C}$ (with a mean average $\mathrm{BOD}_{t}>99,000 \mathrm{mg} / \mathrm{L}$ from $k_{1} @ T=25^{\circ} \mathrm{C}$ and a mean minimum $\mathrm{BOD}_{t}<88,000 \mathrm{mg} / \mathrm{L}$ from $k_{1} @ T=25^{\circ} \mathrm{C}$ ), as plotted in Figures 3(b), 3(d), and 3(f). Thus, industrial wastewater $\mathrm{BOD}_{t}$ increases with temperature by almost $+2 \mathrm{mg} / \mathrm{L}$ to $+3 \mathrm{mg} / \mathrm{L}$ per every $1^{\circ} \mathrm{C}$, justifying the impact of temperature on $\mathrm{BOD}_{t}$ as suggested. Again, the power relationships refer to the continuous organic decomposition rates as from equation (1).

The $\mathrm{BOD}_{t}$ for domestic wastewater influents were observed with a clear increase of $\mathrm{BOD}_{t}$ trendline with time, where both average and minimum $\mathrm{BOD}_{t}$ were found to intersect after a long period (60 days). Such behavior like this could be associated with the not low and not high $\mathrm{BOD}_{t}$ values for domestic wastewaters, resulting in semisimilar 
trendlines, which correspond to almost similar organic degradation rates for average and minimum $\mathrm{BOD}_{t}$. Here, the power relationships between $\mathrm{BOD}_{t}$ and time were justified at low and high selected $\mathrm{BOD}_{t}$ from previously analyzed domestic wastewaters as illustrated in Figure 4. Plotted data sets showed a mean range of an average $\mathrm{BOD}_{t} \approx 130-260 \mathrm{mg} /$ $\mathrm{L}$ and a minimum $\mathrm{BOD}_{t} \approx 50-170 \mathrm{mg} / \mathrm{L}$ from $k_{1} @ T=20^{\circ} \mathrm{C}$, as plotted in Figures 4(a), 4(c), and 4(e). Similarly, the same analysis was carried out with $k_{1} @ T=25^{\circ} \mathrm{C}$ to find the impact of temperature on the $\mathrm{BOD}_{t}$ mean ranges, which was found to increase the initial $\mathrm{BOD}_{t}$ (at $t=0$ ) by $+20 \mathrm{mg} / \mathrm{L}$ or $25 \%$ more than that of $k_{1} @ T=20^{\circ} \mathrm{C}$ (with a mean range of an average $\mathrm{BOD}_{t} \approx 150-250 \mathrm{mg} / \mathrm{L}$ and a minimum $\mathrm{BOD}_{t} \approx$ $70-160 \mathrm{mg} / \mathrm{L}$ from $k_{1} @ T=25^{\circ} \mathrm{C}$ ), as plotted in Figures 4(b), 4(d), and 4(f). Accordingly, it has been found that domestic wastewater $\mathrm{BOD}_{t}$ increases with temperature by almost $+4 \mathrm{mg} / \mathrm{L}$ per every $1^{\circ} \mathrm{C}$ while having shorter required oxidation times at higher temperatures to achieve a nearcomplete organic oxidation rate from utilizing the introduced $\mathrm{O}_{2}$ in wastewater. Again, as discussed earlier, the power relationships refer to the continuous organic decomposition rates as illustrated in equation (1).

From correlating the average $\mathrm{BOD}_{5} / \mathrm{COD}$ ratios to the calculated existing $\mathrm{DO}_{5}$ concentration at $60-70 \%$ oxygen consumption rates, we established the optimum df to be taken into consideration before experimentation for $\mathrm{BOD}_{t}$ analysis of various wastewaters. The step $\mathrm{V}$ center connection lines (using ORIGIN software), illustrated as solid red lines in Figure 5, show the optimum from df points with an exact average of $\mathrm{df} \approx 9.2$ for storm wastewater (STM), $\mathrm{df} \approx$ $12 \times 10^{3}$ for industrial wastewater (IND), and $\mathrm{df} \approx 18.5-28.5$ for domestic wastewater (DOM). The importance of $\mathrm{df}$ numbers arises from its usefulness as a starting point for wastewater operators and engineers to select the ideal df that would ensure the success of the experimental (sampling) analysis of $\mathrm{BOD}_{t}$ of various wastewaters for quantification of organic decomposition rates attributed to the introduced oxygen amounts. Despite that the $\mathrm{DO}_{5}$ parameter values were assumed to be constant at different observed $\mathrm{BOD}_{5}$ (due to the consideration of $60-70 \%$ oxygen consumption rates according to the literature $[13,16,17])$, this average oxygen consumption rate would give the best prediction towards estimating $\mathrm{df}$ values for each of the studied wastewater types. In other words, the relationships between average $\mathrm{BOD}_{5}$ vs. $\mathrm{df}$, and $\mathrm{BOD}_{5}$ vs. $\mathrm{DO}_{5}$ were found to be both following linear trends with an increase in $\mathrm{df}$ when $\mathrm{BOD}_{5}$ becomes higher. According to the previously mentioned "standard methods for water \& wastewater examination," dilution techniques should be done by creating five samples with several dilutions with at least two bottles giving acceptable minimum DO depletion $(>2 \mathrm{mg} / \mathrm{L}$ uptake after a 5-day incubation period) and residual limits (>1 mg/L) [18]. The plotted linear regressions are useful to facilitate the experimentation and analysis of wastewater samples for optimum selection of $\mathrm{df}$ that corresponds to the $\mathrm{BOD}_{5}$ and $\mathrm{DO}_{5}$ levels of wastewater influents. Meanwhile, finding the relationship between average $\mathrm{BOD}_{5}$ and $\mathrm{COD}$ is going to give much accurate and rapid analysis because such $\mathrm{BOD}_{5} /$ $\mathrm{COD}$ ratios are known to serve as a guide in selecting proper dilutions for influents/effluents for the wastewater type of interest.

The average $\mathrm{BOD}_{5} / \mathrm{COD}$ ratios for various studied wastewater types (effluents) have been estimated as illustrated in Figure 6(a). Storm wastewater reserved the minimum $\mathrm{BOD}_{5} / \mathrm{COD}$ ratio among the three wastewater types, which indicates existing of lower amounts of organic compounds (as compared to chemicals) in storm wastewater effluents. Storm, industrial, and domestic wastewaters had an average range of $\mathrm{BOD}_{5} / \mathrm{COD}$ ratios of $0.1 \sim 0.35$, $0.36 \sim 0.5$, and $0.4 \sim 0.48$, respectively. Obtaining the average $\mathrm{BOD}_{5} / \mathrm{COD}$ ranges are very useful since they can be used as indicator tools that would help experimentalists to accomplish accurate sampling analysis. Furthermore, using the corresponding $\mathrm{df}$ values would allow reaching an optimum design for the treatment of a certain type of influent (or even a mixed influent) in specific wastewater treatment plants. Precisely, the reported exact $\mathrm{df}$ averages in Figure 6(b) were justified from our analysis to be the initial trials used for $\mathrm{BOD}_{t}$ experimental analysis. This would allow supplying the required oxygen amounts to optimally control and disinfect microbiological contamination in wastewaters. Industrial wastewater had the highest average $\mathrm{BOD}_{5}$ and COD values in the order of $10^{3}$, while storm wastewater had much less $\mathrm{BOD}_{5}$ and $\mathrm{COD}$ than that of domestic wastewater, illustrated in Figure 6(b), explaining the reasons for having the lowest $\mathrm{BOD}_{5} / \mathrm{COD}$ ratio for storm wastewater as shown in Figure 6(a). This has been also confirmed from the determined average $\mathrm{BOD}_{5} / \mathrm{COD}$ ratios from the various studied wastewater treatment plants presented in Figure 6(c), which were calculated from the previously conducted $\mathrm{BOD}_{t}$ analysis of wastewater influents used in generating such valuable and accurate standardized guidance and operation charts available in Figures 5 and 6 for quality control engineers who might not need to conduct the laboratory experiments prior taking design decisions.

The correlation of both $\mathrm{df}$ and $\mathrm{DO}_{5}(\mathrm{mg} / \mathrm{L})$ to the organic decomposition rates of the organic pollutants that exist in various wastewater types has been studied and plotted in Figure 7. As a rule of thumb, it is proven that there will be always a proportional relationship between existing oxygen (translated as $\mathrm{DO}_{5}$ content) and consumption or organic degradation whereas that the higher the $\mathrm{DO}_{5}$ there in the water, the more the organic decomposition occurs, as mathematically expressed previously in equation (3). One may observe that the $\mathrm{df}$ values here had the same optimum $\mathrm{df}$ average values for each wastewater type as predicted from Figure 5, with $\mathrm{df} \approx 9.2$ for storm wastewater (STM), $\mathrm{df} \approx$ $12 \times 10^{3}$ for industrial wastewater (IND), and $\mathrm{df} \approx 18.5-28.5$ for domestic wastewater (DOM). Moreover, $\mathrm{df}$ found to have an approximate range of $4.5-13.5,1-22 \times 10^{3}$, and 12-35 for STM, IND, and DOM wastewater types, respectively, which can be used as a guidance or a reliable reference when diluting a specific wastewater sample for $\mathrm{BOD}_{t}$ sampling analysis. It is clear that the storm wastewater had the lowest $\mathrm{df}$ range and minimum $\mathrm{df}$ optimum average because of its lower $\mathrm{BOD}_{5}$ as well as $\mathrm{BOD}_{5} / \mathrm{COD}$ ratio, as shown in Figure 6, thus indicating the low quantity of existing organic constituents in storm wastewater influents 


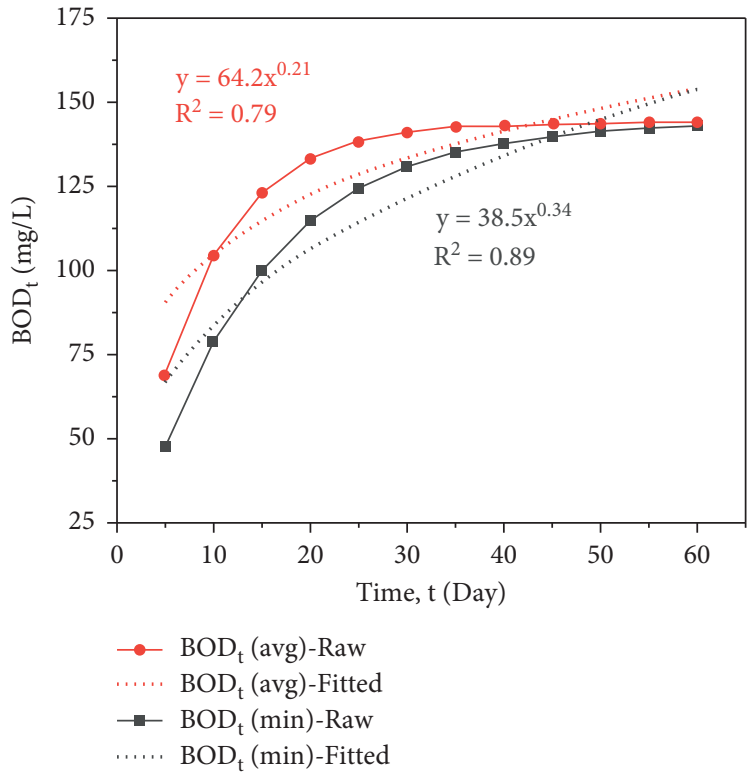

(a)

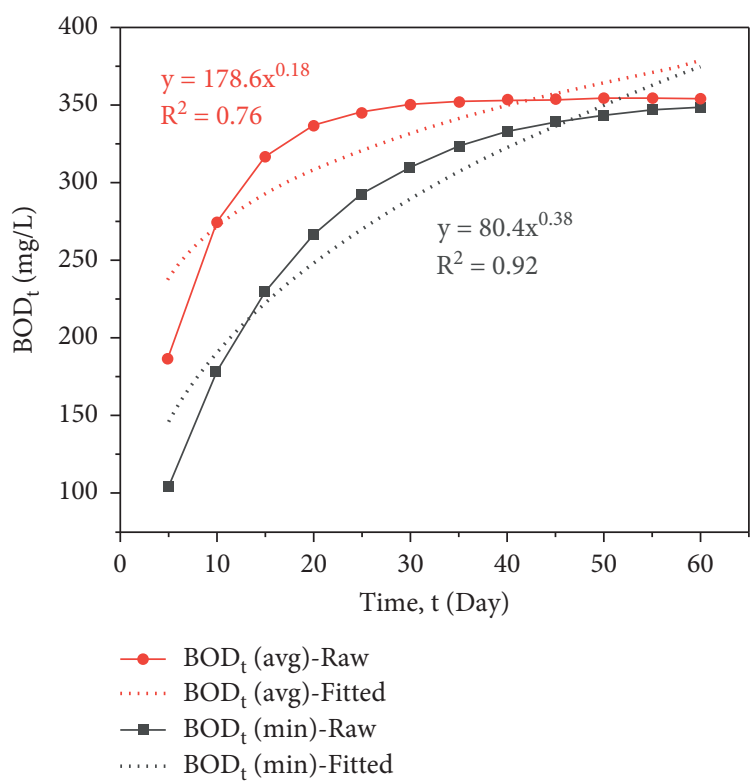

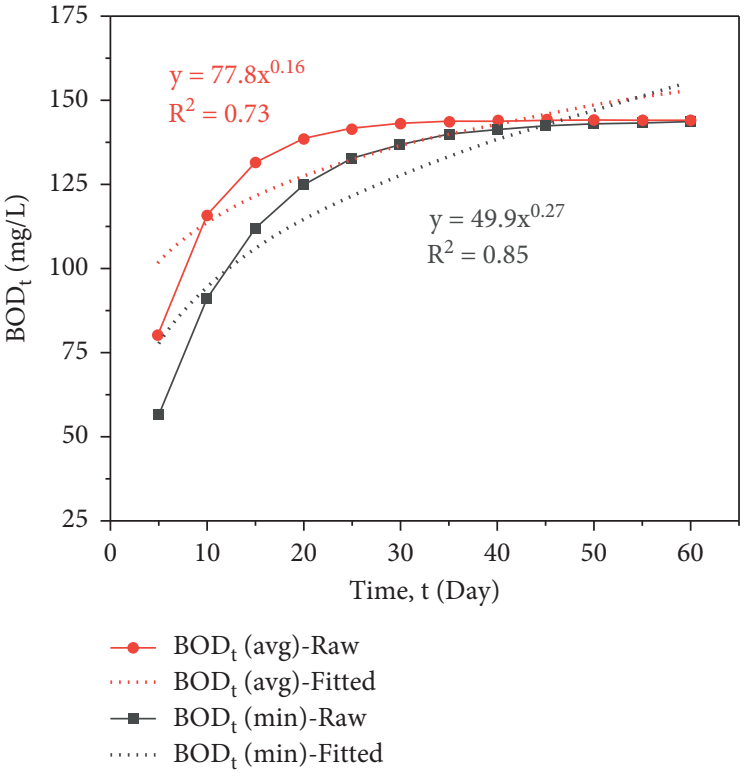

(b)

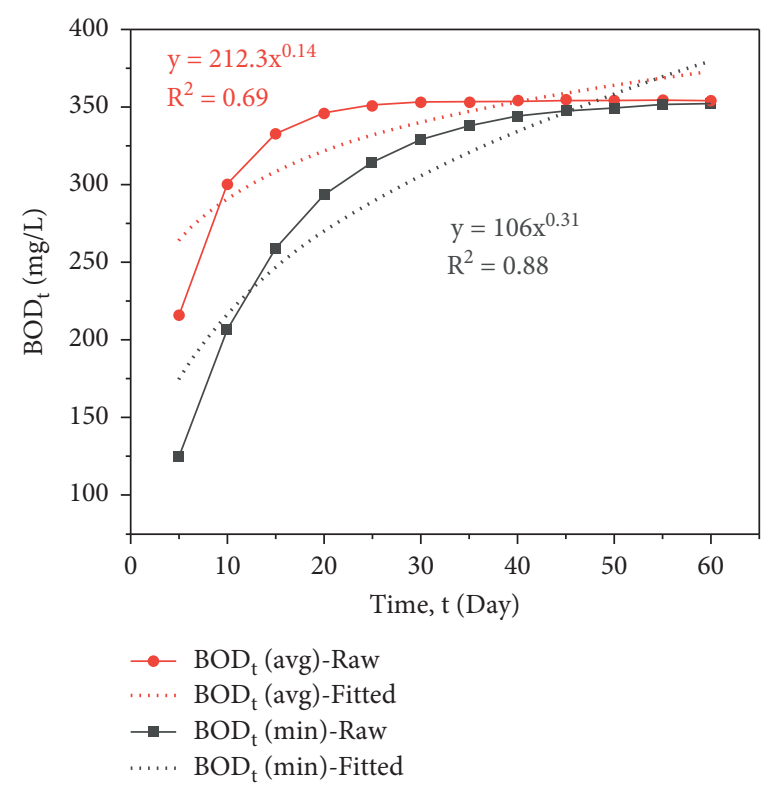

(c)

(d)

Figure 4: Continued. 


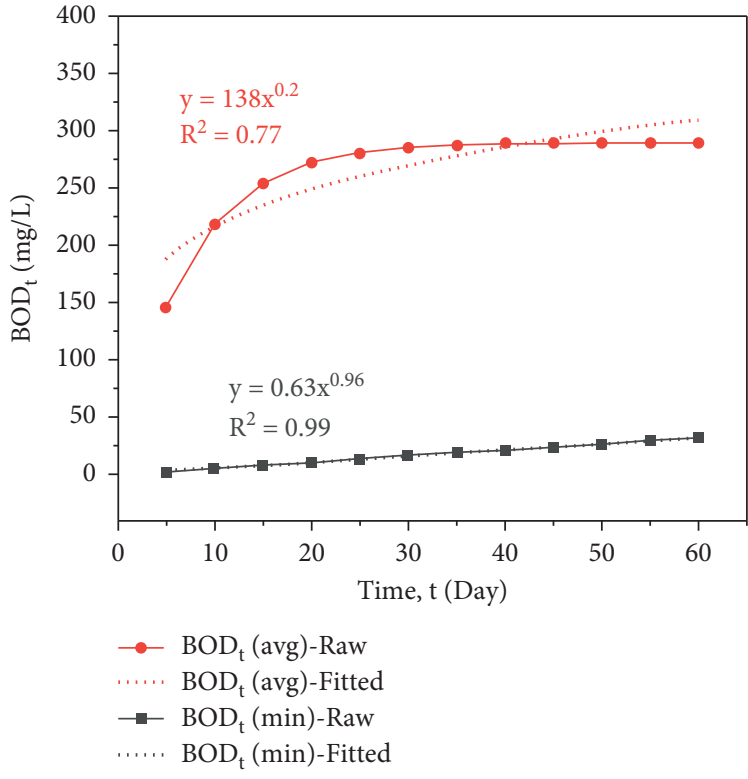

(e)

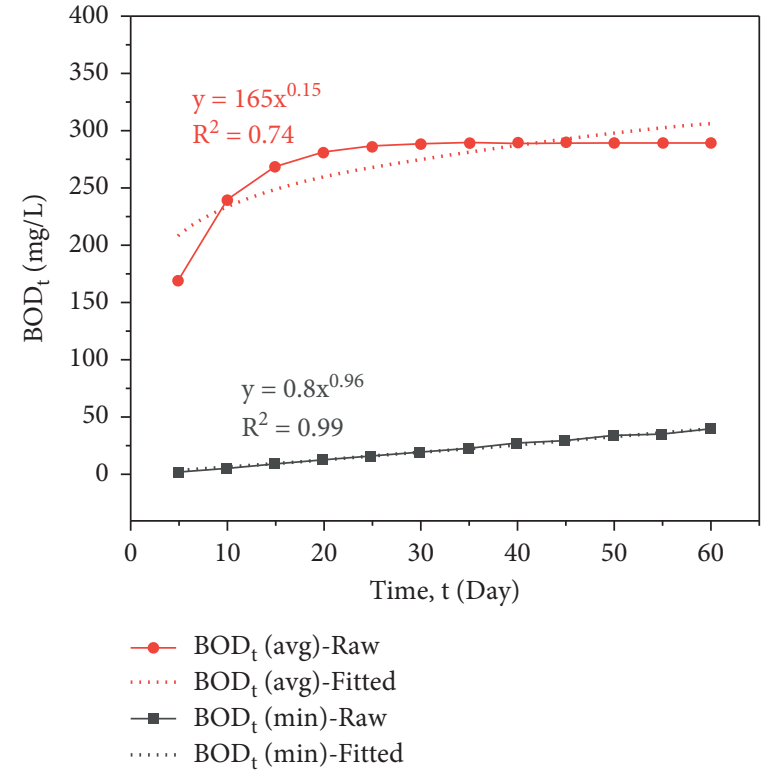

(f)

FIGURE 4: The determined fitted power relationships between $\mathrm{BOD}_{t}$ and time for 60 days of minimum and average $\mathrm{BOD}_{t}$ values collected from analysis of influents in various selected domestic wastewater treatment plants: $(\mathrm{a}, \mathrm{b})$ North Sewage domestic wastewater treatment plant with $k_{1} @ T=20^{\circ} \mathrm{C}$ and $k_{1} @ T=25^{\circ} \mathrm{C}$, respectively; (c, d) Al-Diwaniyah domestic wastewater treatment plant with $k_{1} @ T=20^{\circ} \mathrm{C}$ and $k_{1}$ @ $T=25^{\circ} \mathrm{C}$, respectively; and (e,f) Jordan domestic wastewater treatment plant with $k_{1} @ T=20^{\circ} \mathrm{C}$ and $k_{1} @ T=25^{\circ} \mathrm{C}$, respectively.

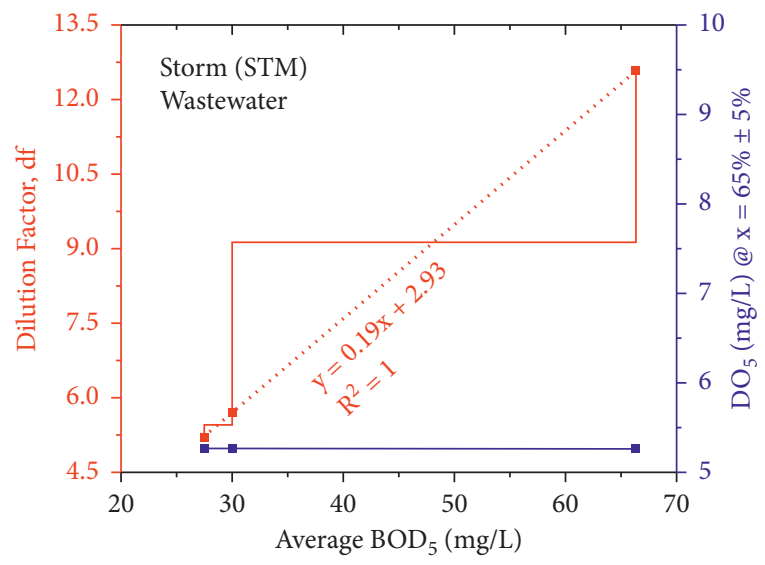

(a)

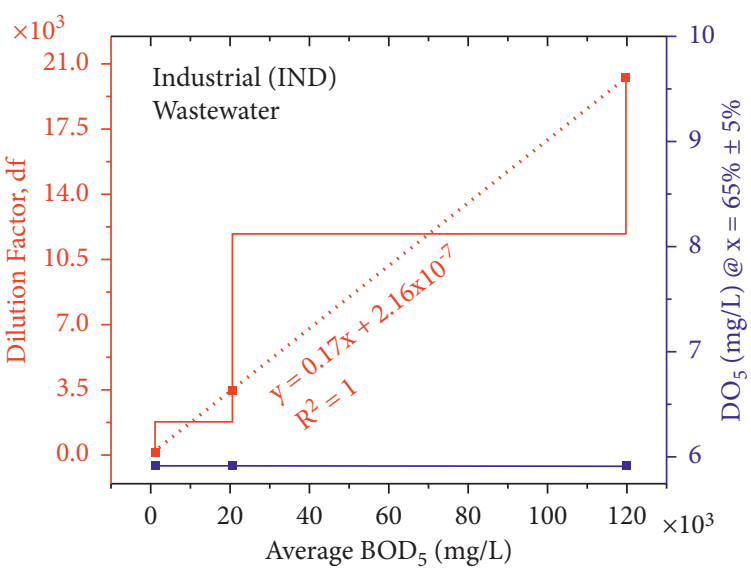

(b)

Figure 5: Continued. 


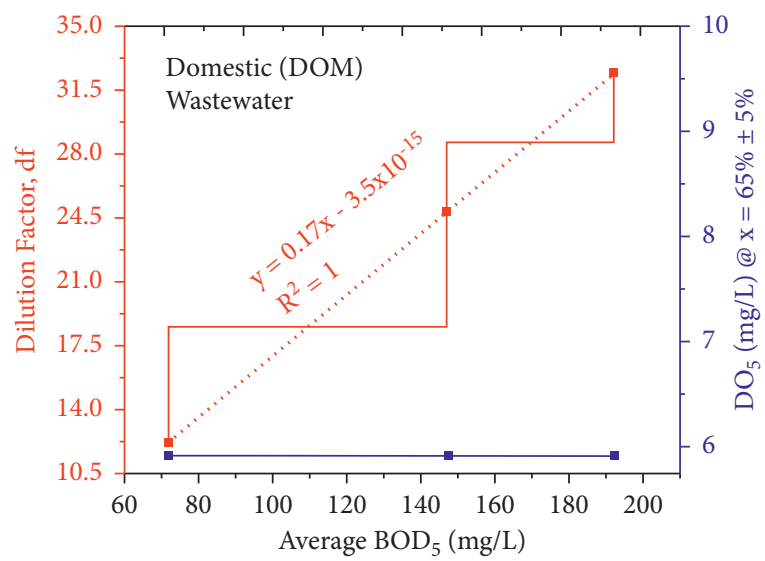

(c)

Figure 5: The average 5-day dissolved oxygen $\left(\mathrm{DO}_{5}\right)$ and the calculated experimental dilution factor (df), used in the $\mathrm{BOD}_{t}$ experimental analysis, correlated to the observed average $\mathrm{BOD}_{5}$ via linear relationships for various wastewater influents: (a) storm wastewater (STM) where average $\mathrm{BOD}_{5}$ values were taken from Poland, Luxembourg, and Nigeria storm wastewater treatment plants; (b) industrial wastewater (IND) where average $\mathrm{BOD}_{5}$ values were taken from GGL, Coca-Cola, and Kumasi Abattoir industrial wastewater treatment plants; (c) domestic wastewater $(\mathrm{DOM})$ where average $\mathrm{BOD}_{5}$ values were taken from North Sewage, Al-Diwaniyah, and Jordan domestic wastewater treatment plants. Note that the use of step V center connection lines (using ORIGIN software) in demonstrating the df points shows an exact average of $\mathrm{df} \approx 9.2$ for $\mathrm{STM}, \mathrm{df} \approx 12 \times 10^{3}$ for $\mathrm{IND}$, and $\mathrm{df} \approx 18.5-28.5$ for DOM that should be used as optimal starting trials in the experimental analysis of $\mathrm{BOD}_{t}$ of various wastewaters.

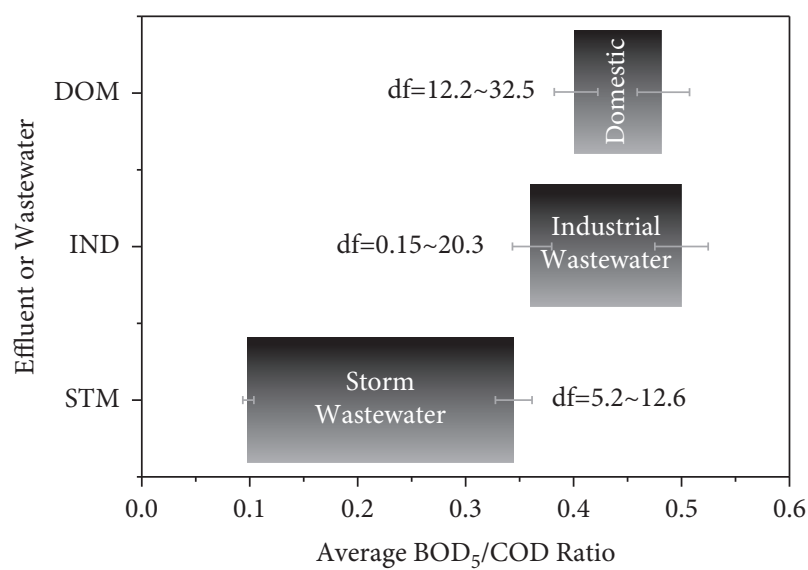

Average $\mathrm{BOD}_{5} / \mathrm{COD}$ Ratio

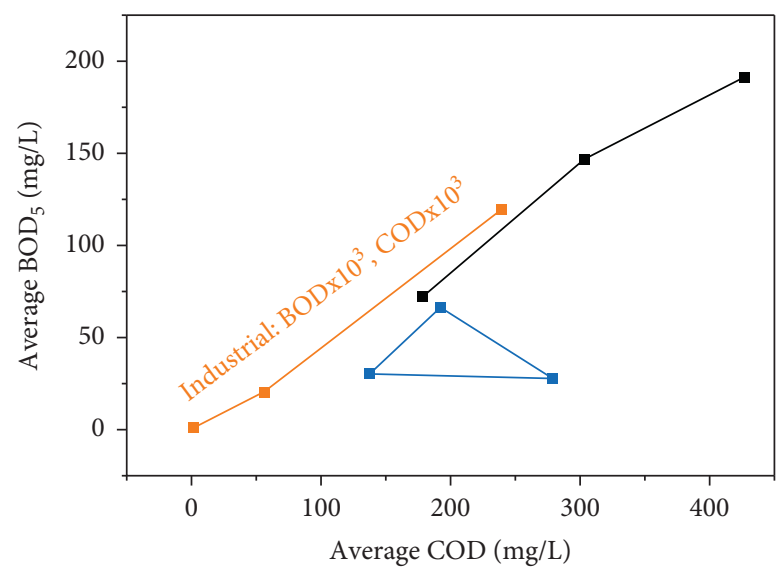

$\longrightarrow$ Storm (STM) Wastewater

- Industrial (IND) Wastewater

- Domestic (DOM) Wastewater

(a)

FIgURE 6: Continued. 


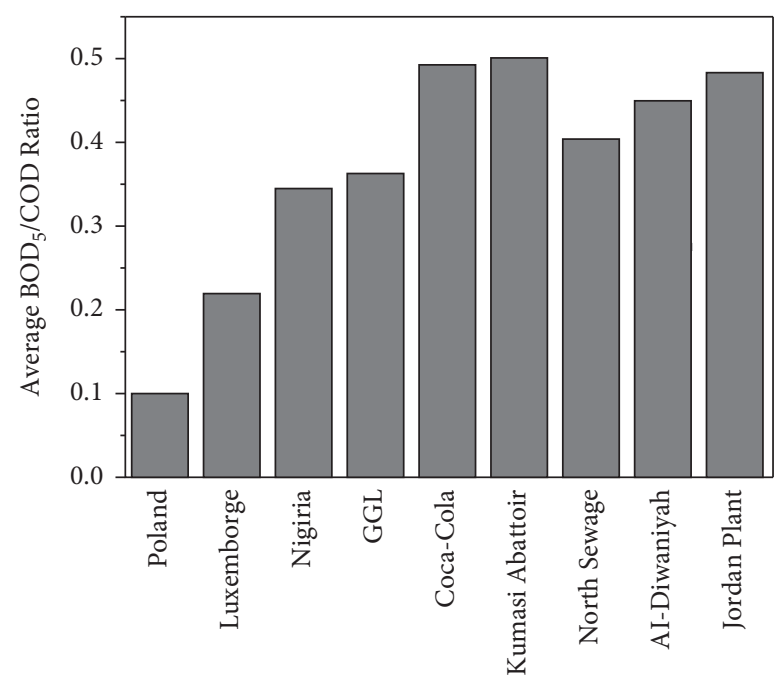

(c)

FIGURE 6: Dilution factor (df) correlated to average $\mathrm{BOD}_{5} / \mathrm{COD}$ ratios and the estimated average values for the different studied wastewater effluents as influents to various wastewater treatment plants: (a) the average $\mathrm{BOD}_{5} / \mathrm{COD}$ ratio ranges found from critical analysis and carried out BOD-related calculations for the three wastewater types, with the obtained df possible ranges to be used as trials in the experimental steps (IND, $\times 10^{3}$ ); (b) a comparison between different wastewater characteristics in terms of their calculated average $\mathrm{BOD}_{5}$ corresponding to the wastewater average COD, note that reported average $\mathrm{df}$ values here are suggested to be the initial trials used for BODt experimental analysis; and (c) determined average $\mathrm{BOD}_{5} / \mathrm{COD}$ ratios from the various studied wastewater treatment plants.

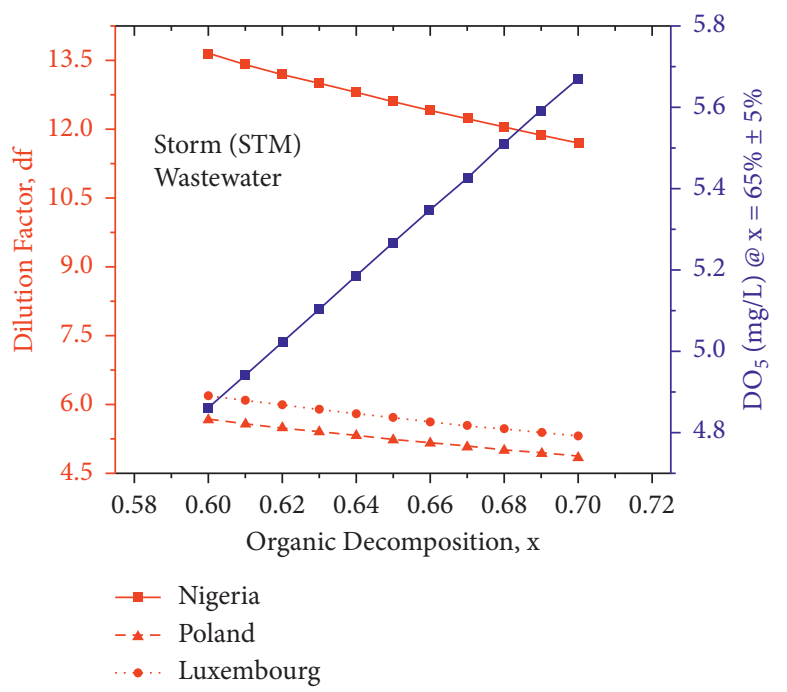

(a)

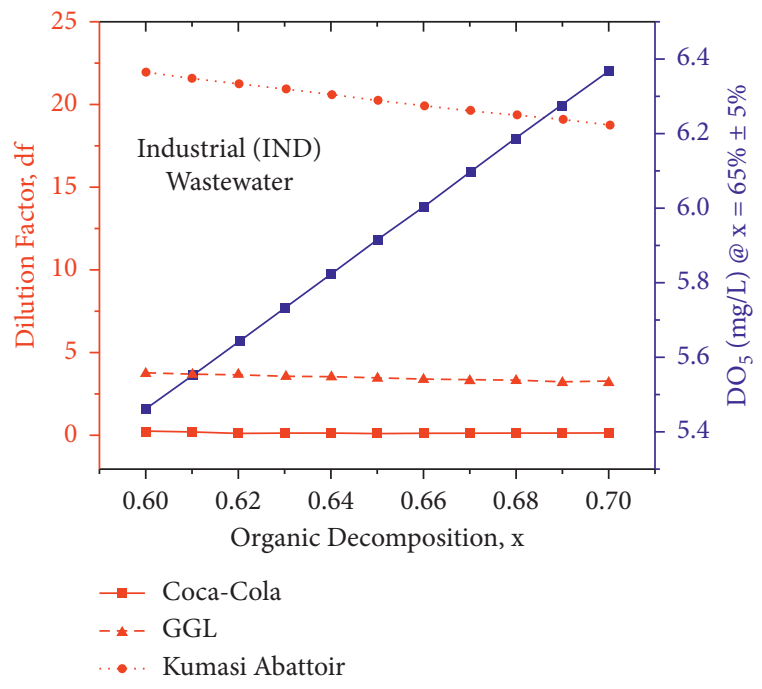

(b)

Figure 7: Continued. 


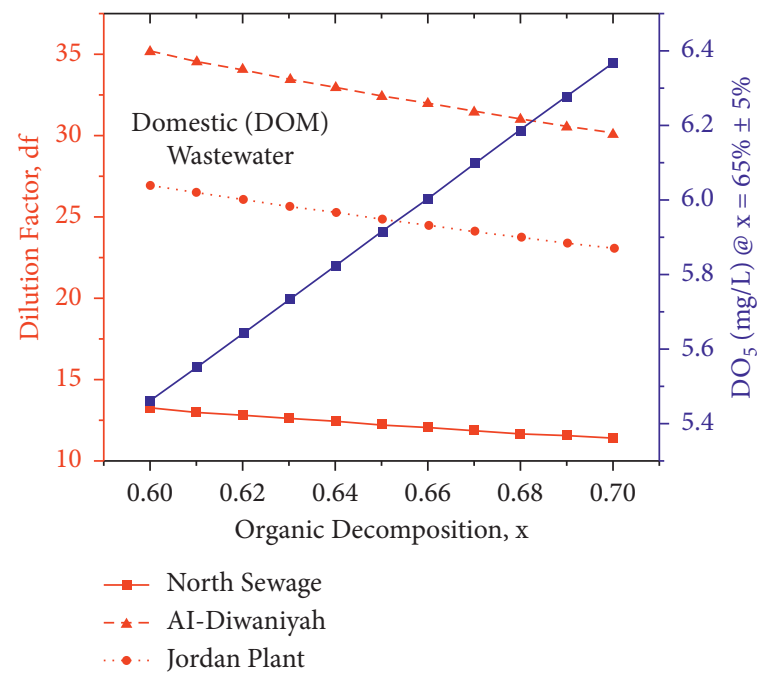

(c)

Figure 7: The estimated organic decomposition rate $(x)$ correlated to the calculated 5-day dissolved oxygen $\left(\mathrm{DO}_{5}\right)$ and experimental dilution factor (df) for various wastewater influents: (a) storm wastewater (STM) data analysis from water characteristics in Poland, Luxembourg, and Nigeria storm wastewater treatment plants; (b) industrial wastewater (IND) data analysis from water characteristics in GGL, Coca-Cola, and Kumasi Abattoir industrial wastewater treatment plants; and (c) domestic wastewater (DOM) data analysis from water characteristics in North Sewage, Al-Diwaniyah, and Jordan domestic wastewater treatment plants.

TABLE 1: Estimated average and minimum $\mathrm{BOD}_{t}$ and water temperature rise impact with the corresponding $\mathrm{BOD}_{5} / \mathrm{COD}$, experimental dilution factor ( $\mathrm{df})$, and average $\mathrm{df}$ range for the various studied wastewater types.

\begin{tabular}{|c|c|c|c|c|c|c|}
\hline $\begin{array}{l}\text { Wastewater type } \\
\text { (Abbrev.) }\end{array}$ & $\begin{array}{l}\mathrm{BOD}_{t}^{*} \\
(\mathrm{mg} / \mathrm{L}) \\
\end{array}$ & $\begin{array}{c}\text { Min. } \mathrm{BOD}_{t} \\
(\mathrm{mg} / \mathrm{L})\end{array}$ & $\begin{array}{c}\mathrm{BOD}_{t}{ }^{*}(\mathrm{mg} / \mathrm{L}) \text { vs. temperature (per } \\
\left.\text { every } 1^{\circ} \mathrm{C}\right)\end{array}$ & $\mathrm{BOD}_{5} / \mathrm{COD}^{*}$ & $\mathrm{df}^{*}$ & df range* \\
\hline Storm (STM) & $40-78$ & $16-55$ & +1.2 & $0.1 \sim 0.35$ & 9.2 & $4.5-13.5$ \\
\hline Industrial (IND) & $>90,000$ & $<80,000$ & +2 to +3 & $0.36 \sim 0.5$ & $12 \times 10^{3}$ & $1-22$ \\
\hline Domestic (DOM) & $130-260$ & $50-170$ & +4 & $0.4 \sim 0.48$ & $18.5-28.5$ & $12-35$ \\
\hline
\end{tabular}

* Average values from $k_{1} @ T=20^{\circ} \mathrm{C}$, which correspond to the selected wastewater type experimental results.

to be treated at storm wastewater treatment plants. However, the obtained df mean values can serve as a good start for wastewater plant engineers to reach an optimum cost-effective $\mathrm{DO}_{5}$ concentration that would ensure maximum organic decomposition without the addition of excess or unnecessary extra oxygen amounts (Figure 7).

Table 1 shows the summarized calculated results obtained from the collected experimental data sets based on the nine selected plants, as shown in Figure 6(c), for the three studied different wastewater types. All the data analysis has been conducted at the average wastewater temperature $\left(T=20^{\circ} \mathrm{C}\right)$ that is assumed to be similar to the average surrounding temperature. Domestic wastewater has low $\mathrm{BOD}_{5} / \mathrm{COD}$ values since $\mathrm{BOD}_{5}$ (organic contents) was found to be always less than half of the existing nonorganic contaminations (COD or chemicals contents) in wastewater. Typical values for the ratio of $\mathrm{BOD}_{5} / \mathrm{COD}$ for untreated municipal wastewater is 0.3 to 0.8 and If the $\mathrm{BOD}_{5} / \mathrm{COD}>0.5$, the waste is considered easily treatable by biological means.

Knowing that UBOD is a parameter for water quality assessment that quantifies the oxygen required for the total biochemical degradation of organic matter by aquatic microorganisms, the depletion of $\mathrm{DO}_{5}$ is a primary water quality concern since the oxygen level is associated with disinfection (pathogen destruction). The $\mathrm{DO}_{5}$ depletion define the microbial use or consumption (i.e., demand) of oxygen during the aerobic oxidation of electron donors such as readily degradable organic carbon (e.g., sugars as glucose) and ammonia in waters as shown in the simplified reactions equations (5) and (6) [21], ignoring the substrate being incorporated into biomass. The general form of the previous equations for decomposition of organic matter can be written as in equation (7), where the rate of biodegradation can be modeled as a firstorder reaction (i.e., as a function of the remaining oxygen demand). A portion of the organic matter (the growth substrate) is also converted into cell material, or biomass (the catalyst), so its concentration is changing as well [22].

$$
\begin{aligned}
\mathrm{C}_{6} \mathrm{H}_{12} \mathrm{O}_{6}+6 \mathrm{O}_{2} & \longrightarrow 6 \mathrm{CO}_{2}+6 \mathrm{H}_{2} \mathrm{O} \\
\mathrm{NH}_{3}+2 \mathrm{O}_{2} & \longrightarrow \mathrm{NO}_{3}^{-}+\mathrm{H}_{2} \mathrm{O}+\mathrm{H}^{+}
\end{aligned}
$$

organic matter + nutrients $+\mathrm{O}_{2} \longrightarrow \mathrm{CO}_{2}+\mathrm{H}_{2} \mathrm{O}+$ biomass

\section{Conclusion}

We demonstrated the ability to establish empirical correlations between the 5-day biochemical oxygen demand $\left(\mathrm{BOD}_{5}\right)$ 
and organic decomposition in wastewater effluents. Collected data sets from earlier sampling analyses included ultimate biochemical oxygen demand (UBOD) and minimum and average $\mathrm{BOD}_{t}$ along with their reaction rates. With a reaction rate $k_{1} @ T=20^{\circ} \mathrm{C}$, wastewaters would have an average $\mathrm{BOD}_{t}$ of $40-78 \mathrm{mg} / \mathrm{L},>90,000 \mathrm{mg} / \mathrm{L}$, and $130-260 \mathrm{mg} / \mathrm{L}$ for the storm, industrial, and domestic wastewater, respectively. There is a strong correlation and dependence of $\mathrm{BOD}_{t}$ on the water temperature whereas that every $1^{\circ} \mathrm{C}$ added to the water yield in an increase of $+1.2 \mathrm{mg} / \mathrm{L},+2 \mathrm{mg} / \mathrm{L}$ to $+3 \mathrm{mg} / \mathrm{L}$, and $+4 \mathrm{mg} / \mathrm{L}$ in the initial $\mathrm{BOD}_{t}$ values for the storm, industrial, and domestic wastewater, respectively. Thus, there will be shorter oxidation times required at higher temperatures to achieve a near-complete organic oxidation rate. The microorganisms' oxygen uptake rate has to be less than the available oxygen for reduction of BOD. Based on the 60-70\% oxygen consumption rates, the author estimated an optimum average of $\mathrm{df} \approx 9.2$ for storm wastewater (STM), $\mathrm{df} \approx 12 \times 10^{3}$ for industrial wastewater (IND), and $\mathrm{df} \approx 18.5-28.5$ for domestic wastewater (DOM). These $\mathrm{df}$ values can serve as a good start in sampling analysis to reach an optimum costeffective $\mathrm{DO}_{5}$ concentration without the addition of excess oxygen amounts. Such proposed regression equations and standardized guidance charts would bridge the gap between scientific observations and industrial best practices for optimal design and operation to control organic contamination in various wastewater treatment plants.

\section{Data Availability}

The data sets generated during and/or analyzed during the current study are available from the author on reasonable request.

\section{Conflicts of Interest}

The author declares no conflicts of interest.

\section{Acknowledgments}

The author acknowledges the Deanship of Scientific Research (DSR) at King Abdulaziz University (KAU) for their support and motivation to complete this work.

\section{References}

[1] C. J. Vörösmarty, P. B. McIntyre, M. O. Gessner et al., "Erratum: global threats to human water security and river biodiversity," Nature, vol. 4687321 pages, 2010.

[2] Y. Wen, G. Schoups, and N. Van De Giesen, "Organic pollution of rivers: combined threats of urbanization, livestock farming and global climate change," Scientific Reports, vol. 7, p. 43289, 2017.

[3] H. Maddah and A. Chogle, "Biofouling in reverse osmosis: phenomena, monitoring, controlling and remediation," $A p$ plied Water Science, vol. 7, no. 6, pp. 2637-2651, 2017.

[4] H. A. Maddah, "Numerical analysis for the oxidation of phenol with $\mathrm{TiO} 2$ in wastewater photocatalytic reactors," Engineering, Technology \& Applied Science Research, vol. 8, no. 5, pp. 3463-3469, 2018.
[5] A. Vob, J. Alcamo, I. Bärlund et al., "Continental scale modelling of in-stream river water quality: a report on methodology, test runs, and scenario application," Hydrological Processes, vol. 26, no. 16, 2012.

[6] J. G. Langeveld, H. J. Liefting, and F. C. Boogaard, "Uncertainties of stormwater characteristics and removal rates of stormwater treatment facilities: implications for stormwater handling," Water Research, vol. 46, pp. 6868-80, 2012.

[7] D. Lapiński and J. Wiater, "Contamination content introduced with rain water to the rivers after they have been cleaned in separators of petroleum compounds," E3S Web of Conferences, vol. 30, 2018.

[8] O. O. Adedeji and Olayinka, "Heavy metal concentrations in urban stormwater runoff and receiving stream," Journal of Environment and Earth Science, vol. 3, no. 7, pp. 141-150, 2013.

[9] B. Nagel and L. M. Gierasch, "Glossary for chemists of terms used in biotechnology (IUPAC recommendations 1992)," Pure and Applied Chemistry, vol. 64, no. 1, pp. 143-168, 1992.

[10] O. Alagha, A. Allazem, A. A. Bukhari, I. Anil, and N. D. Mu'azu, "Suitability of SBR for wastewater treatment and reuse: pilot-scale reactor operated in different anoxic conditions," International Journal of Environmental Research and Public Health, vol. 17, no. 5, p. 1617, 2020.

[11] A. M. Al-Sulaiman and B. H. Khudair, "Correlation between Bod5 and cod for Al-diwaniyah wastewater treatment plants to obtain the biodigrability indices," Journal of Biotechnology, vol. 15, no. 2, 2018.

[12] F. A. Abdulla, A. Alfarra, H. A. Qdais, and B. Sonneveld, "Evaluation of wastewater treatment plants in Jordan and suitability for reuse," Academia Journal of Environmental Sciences, vol. 4, no. 7, 2016.

[13] M. E. Lewis, Dissolved Oxygen: U.S. Geological Survey Techniques of Water-Resources InvestigationsUSGS, Reston, Virginia, US, 2006.

[14] C. R. Hach, R. L. Klein Jr, and Gibbs, "Biochemical oxygen demand," Technical Monograph, vol. 7, 1997.

[15] D. H. Caldwell and W. F. Langelier, "Manometric measurement of the biochemical oxygen demand of sewage," Sewage Works Journal, vol. 20, no. 2, pp. 202-18, 1948.

[16] W. Metcalf and C. Eddy, Metcalf and Eddy Wastewater Engineering: Treatment and Reuse, Wastewater Eng. Treat. Reuse McGraw Hill, New York, NY, USA, 2003.

[17] N. Anggraini and H. Herdiansyah, "COD values for determining BOD5 dilution factor in faecal sludge waste - case study on the duri kosambi faecal sludge treatment plant in DKI Jakarta province," AIP Conference Proceedings, vol. 2120, 2019.

[18] APHA, AWWA, and WEF, Standard Methods for Examination of Water and Wastewater, Washingt. Am. Public Heal. Assoc., Seattle, Washington, 2012.

[19] H. A. Maddah, M. Bassyouni, M. H. Abdel-Aziz, M. S. Zoromba, and A. F. Al-Hossainy, "Performance estimation of a mini-passive solar still via machine learning," Renewable Energy, vol. 162, 2020.

[20] H. A. Maddah, "Simulating fouling impact on the permeate flux in high-pressure membranes," International Journal of Advanced And Applied Sciences, vol. 8, no. 8, pp. 1-8, 2021.

[21] J. J. Pauer, J. R. Mihelcic, and M. R. Penn, Environmental and Ecological Chemistry-Biochemical Oxygen Demand, (C) Encyclopedia of Life Support Systems (EOLSS), Wisconsin, USA, 2017.

[22] T. G. Ellis, Environmental and Ecological Chemistry-Chemistry of Wastewater, (C) Encyclopedia of Life Support Systems (EOLSS), Ames, Iowa, USA, 2004. 